\title{
AGAMA DAN KEKERASAN TERHADAP PEREMPUAN (ANALISIS GEN DER DAN FILSAFAT TAOISME-ISLAM)
}

\author{
Fatrawati Kumari \\ Dosen Tetap Fakultas Ushuluddin IA IN A ntasari Banjarmasin Kalimantan Selatan \\ fatra_wt@yahoo.com
}

\begin{abstract}
A bstract: Violence against women often occurs in various fields of life. The violence is a product of a patriarchal culture that is not just touching the social sphere, but also venturing into religious territory. Religion is considered as a justification and the things that make the practice of violence against women becomes a habit. View of gender bias in the various dimensions of life, including religion also took part in the practice of letting the violence against women, even seen as root causes of the violence. Through the analysis of gender and Taoism-Islam, the issue of violence against women is trying to find a comprehensive explanation for the violence seen not only physicallyquantitative, but also spiritually-qualitative. Relation equal reciprocity in the relationship becomes important bid proposed Islamic gender analysis and Taoism.
\end{abstract}

Keywords: violence, gender, Taoism-Islam

\begin{abstract}
A bstrak: Kekerasan kerap kali terjadi terhadap perempuan di berbagai bidang kehidupan. Kekerasan merupakan produk budaya patriarki yang tidak saja menyentuh wilayah sosial, melainkan juga merambah ke wilayah agama. Agama dianggap sebagai jastifikasi dan pelanggeng praktek kekerasan terhadap perempuan. Pandangan bias gender dalam berbagai dimensi kehidupan, termasuk agama turut ikut andil dalam pembiaran praktek kekerasan terhadap perempuan, bahkan dipandang sebagai akar persoalan terjadinya kekerasan. Melalui analisis gender dan Taoisme-Islam, masalah kekerasan terhadap perempuan berupaya menemukan penjelasan yang komprehensif karena kekerasan dilihat tidak saja secara fisik-kuantitatif, melainkan juga secara spiritual-kualitatif. Relasi yang setara dalam hubungan kesalingan menjadi tawaran penting yang diajukan analisis gender dan Taoisme Islam.
\end{abstract}

Kata Kunci: kekerasan, gender, Taoisme-Islam

\section{PENDAHULUAN}

Setiap ada pembicaraan tentang agama dan perempuan selalu tersirat semacam dugaan, bahwa agama memiliki keterkaitan erat dengan ketidakadilan gender. Agama apapun, termasuk Islam seolah menjadi pembenar sekaligus pembiar terhadap setiap tindakan yang "tidak elok" terhadap kelompok sosial yang lemah, seperti perempuan. Ada kenyataan yang membiarkan perempuan dijadikan "komoditi" melalui pengiriman TKW (Tenaga Kerja Wanita) di sektor nonformal ke negara-negara yang jelas-jelas "kurang bersahabat" dengan TKW. Selama puluhan tahun perempuan dibiarkan "diperjualbelikan" ke berbagai negara dalam berbagai tampilan, mulai dari PRT (Pembantu Rumah Tangga) hingga wanita penghibur. Perempuan yang dipekerjakan juga beragam, mulai dari anak-anak di bawah umur hingga 
Fatrawati Kumari: Agama dan Kekerasan Terhadap Perempuan (Analisis Gender dan Filsafat Taoisme-Islam)

perempuan dewasa. ${ }^{1}$ Biasanya kepedulian dari pemerintah baru muncul ketika kondisi ekstrim terjadi, seperti penganiayaan yang membuat para TKW cacat seumur hidup atau hukuman gantung yang sampai saat ini masih menanti ratusan TKW Indonesia. ${ }^{2}$

Perempuan di belahan dunia lain dengan latar belakang keyakinan dan tradisi beragam mengalami kekerasan dalam rumah tangga yang mendapat pembenaran oleh budaya setempat. Di Indiaterjadi 135kasusperempuan bunuh diri sepanjang tahun 2011. Angka ini terus mengalami peningkatan hingga perempuan bunuh diri mencapai rata-rata 15 (lima belas) orang per jam. Penyebab bunuh diri selain karena faktor ekonomi, seperti terbelit hutang atau tidak mampu membayar mas kawin terhadap calon mempelai laki-laki juga akibat KDRT (Kekerasan Dalam Rumah Tangga) baik secara fisik maupun mental. ${ }^{3}$

Masih di India, tepatnya di Pradish, sebuah distrik negara bagian Uttar, para suami membagi-bagi istri secara paksa kepada saudara laki-laki atau teman karena jumlah laki-laki di sana jauh lebih banyak dari perempuan. Hal ini terjadi karena bayibayi perempuan banyak yang diaborsi atau dihindari oleh keluarga-keluarga. Sebaliknya, bayi-bayi laki-laki lebih dikehendaki karena dianggap lebih utama, lebih mulia dan lebih membanggakan keluarga.Akibat pandangan tersebut, perempuan di wilayah tersebut rentan terhadap berbagai bentuk kekerasan lain, seperti perkosaan dan perdagangan perempuan. ${ }^{4}$

Belum terlalu lama, tepatnya tanggal 30 Oktober 2011 di Negara kita sendiri, wilayah Muara Bungo, Jambi, Sumatera, terjadi kekerasan terhadap perempuan yang sangat memprihatinkan. Seorang perempuan korban perkosaan yang saat itu dalam kondisi trauma dan lemah yang sedang memerlukan pertolongan cepat darurat secara medis dan keamanan malah ditambah diperkosa oleh dua petugas Satuan Polisi Pamong Praja (Satpol PP). ${ }^{5}$

Beberapa kejadian tersebut hanya contoh dari sekian banyak kasus kekerasan terhadap perempuan yang kebetulan ditemukan media sebuah koran lokal Banjarmasin. Masih banyak kasus kekerasan lain di berbagai negara yang diliput berbagai media dunia cetak dan elektronik yang memberitakan kekerasan terhadap perempuan setiap hari. Fakta telah menunjukkan, bahwa kekerasan terhadap perempuan bukan merupakan mitos, bukan pula sekedar cerita-cerita pepesan kosong masa lalu, tetapi benar-benar kenyataan yang terjadi sejak dulu hingga saat ini. Organisasiorganisasi perempuan yang benar-benar peduli terhadap persoalan kekerasan terhadap perempuan memiliki data akurat untuk menjelaskan kejadian tersebut. Angka-angka kekerasan terhadap perempuan baik fisik maupun psikis terus mengalami kemajuan mengiringi kemajuan bangsa-bangsa dunia. ${ }^{6}$

Seluruh fakta tersebut diperparah oleh beragam pandangan kurang positif yang mengitari masyarakat sehingga memperburuk keadaan perempuan. Misalnya pandangan yang menyatakan, bahwa seluruh kekerasan yang dialami perempuan terjadi karena "permintaan" korban sendiri.Penampilan, kata-kata, sikap dan anatomi tubuh perempuan dianggap "mengundang" laki-laki untuk melakukan kekerasan 7 . Perempuan dianggap sudah punya potensi salah sehingga apapun yang menimpa perempuan diakibatkan oleh perempuan itu sendiri.Lingkungan dan keyakinan memberikan pembenaran terhadap anggapan-anggapan tersebut. 


\section{PEMBAHASAN}

\section{Posisi Agama Dalam Realitas Sosial}

Pada dasarnya, agama yang diturunkan Tuhan ke muka bumi bersifat mutlak dalam rangka memberi petunjuk bagi umat manusia.Ketika agama yang bersifat mutlak dipahami manusia, maka agama berubah menjadi sebuah pemahaman. Karena berupa pemahaman, sifatnya menjadi relatif mengiringi relatifitas dimensi historisitas manusia. Pemahaman tentang agama selalu terkait dengan struktur sosial dimana agama tersebut berkembang. Struktur sosial patriarki akan menghasilkan pemahaman agama yang juga patriarki. Pandangan yang menempatkan perempuan sebagai "manusia salah" akan melahirkan pemahaman agama yang juga akan memandang perempuan sebagai makhluk Tuhan yang selalu salah. Agama menyejarah dan menjadi sebuah pemahaman tidak dengan begitu saja, melainkan melalui proses dialektis yang bersinggungan dengan budaya, konstruksi sosial dan wacana teologi di setiap komunitas.

Bagaimana proses dialektika sosial secara umum berjalan dapat diperjelas dengan pandangan Berger $^{8}$. Menurut Berger, terdapat tiga tahap dialektis yang terjadi di masyarakat, yaitu eksternalisasi, objektivikasi dan internalisasi. Eksternalisasi adalah wilayah manusia mengekspresikan diri membangun dunianya sendiri. Manusia melalui ekspresi ini memanifestasikan suatu realitas objektif. Pada situasi ini berlangsung tahap objekivikasi yang berproses dalam jangka waktu panjang sehingga membawa pengaruh pada pembentukan perilaku manusia. Ini lah tahap internalisasi yang telah menyentuh kesadaran manusia dalam bertindak. Pemahaman manusia tentang hal apa pun, termasuk tentang agama tidak lepas dari proses dialektis tersebut. Agama dengan demikian selalu bersentuhan dengan tradisi, sejarah dan kemanusiaan yang selalu berubah. Dengan demikian, teologi bukan sekedar ilmu tentang ketuhanan, tetapi secara tersirat mencakup sisi kemanusiaan yang sifatnya antropologis dan kontekstual. Teologi merupakan manifestasi kemuliaan Tuhan yang suci transendental sekaligus profansosiologis karena tersusun dalam historisitas kemanusiaan yang selalu berubah dan baru dengan nilai-nilai luhur yang menjunjung tinggi harkat martabat manusia.

Keluhuran agama teruji oleh cara beragama formal legalistik yang umumnya dianut umat Islam Indonesia. Model beragama Islam Indonesia sejak masa Orde Baru tersebut menemukan bentuknya dalam sebuah

aktivitas yang tersibukkan dengan atribut dan simbol-simbol keagamaan. Tujuannya tidak lain adalah untuk melegitimasi kekuasaan. Adapun di tataran global, ditandai dengan makin menguatnya kelompok konservatif agama. Secara serempak teologi dan fiqih model beragama tersebut berada di garda depan dengan segala ambigunya. Lies membuktikan sikap mendua MUI dan tokohtokoh agama Indonesia melalui fatwa haram perempuan sebagai capres saat Megawati akan mencalonkan diri sekitar tahun 1999. Uniknya, setelah Megawati memperoleh suara terbanyak dan menjadi presiden, sikap mereka berubah melunak. Di wilayah lain, kelompok substantif yang juga berpegang pada teksteks fiqih, seperti Musdah Mulia saat menjadi bagian dalam tubuh Depag (Gender Team Depag) justru berhasil melahirkan dokumen kajian kritis Kompilasi Hukum Islam dengan menggunakan analisis gender. Aktivis HAM (Hak Asasi Manusia) dan demokrasi 
wilayah Cirebon, Faqihuddin Abdul Kodir telah melawan pandangan tentang poligami sebagai sunnah Nabi dan melawannya dengan pandangan, bahwa monogami yang sesungguhnya sunnah $\mathrm{Nabi}^{9}$

Fiqih telah menempatkan perempuan sebagai makhluk domestik dan sementara laki-laki sebagai makhluk publik. Konsekuensi dari posisi tersebut, perempuan semata hanya menjadi objek dan konsumen teks. Fiqih yang semula lahir dengan sifat legal dan sifat pembebasan dalam menghadapi penguasa, berubah menjadi bersekutu dengan penguasa (bahkan dikuasai penguasa) dan menjadi alat penindas bagi perempuan. Sudah saatnya untuk mempertanyakan tentang kemungkinan mengembalikan fiqih sebagaimana spirit awal kelahirannya, yaitu sebagai pembimbing dan etika sosial yang berpihak pada yang lemah, bukan sebagai hukum legal yang berpihak pada yang kuat, seperti penguasa. ${ }^{10}$

\section{Patriarki dalam Analisis Gender}

Kekerasan(violence) terjadi di segalabidang kehidupan perempuan yang termanifestasi dalam bentuk pelecehan seksual, perkosaan, pemukulan, incest (hubungan sedarah), pornografi dan lain sebagainya. Seluruh wujud kekerasan merupakan produk dari budaya patriarki yang menganggap laki-laki sebagai penguasainstitusi sosial dan penguasa atas tubuh perempuan. Kekerasan merupakan sebuah mekanisme yang mempertahankan relasi yang tidak setara di semua aspek kehidupan. ${ }^{11}$

Sejalan dengan Hum, Engineer berpandangan, bahwa kekerasan terhadap perempuan berkaitan erat dengan ketidakadilan'12. Ketidakadilan dalam hal apapun, termasuk ketidakadilan gender akan berpotensi melahirkan kekerasan. Sebaliknya, aspek keadilan selalu mengindikasikan ketentraman karenahanya melalui masyarakat yang adil masyarakat sejahtera yang anti kekerasan akan dapat dilahirkan. ${ }^{13}$ Patriarki yang merupakan ibu kandung kekerasan terhadap perempuan merupakan suatu sistem otoritas laki-laki yang menindas perempuan melalui institusi sosial, polituk dan ekonomi. Patriarki menguasai semua sistem dunia, baik feodal, kapitalis maupun sosialis. Patriarki memiliki kekuatan di dalam dan luar rumah.

Para feminis menggambarkan berbagai model gaya patriarki dalam melakukan subordinasi atas perempuan. Firestone misalnya, mendefinisikan penindasan patriarki sebagai sebuah kontrol laki-laki terhadap reproduksi perempuan, sedangkan feminis sosialismemposisikan dalamkonteksmaterial, yaitu pembagian kerja secara seksual. Heidi Hartman mendefinisikan sebagai serangkaian relasi sosial hirarkis dengan dasar material yang didominasi laki-laki.Feminisme radikal menyamakan patriarki dengan dominasi laki-laki sehingga secara tidak langsung telah menyingkirkan perempuan dari sejarah. Feminis antropologis seperti Michelle Rosaldo menolak definisi patriarki secara universal dan menganggapnya sebagai ahistoris. Seluruh contoh gambaran definisi patriarki yang dikemukakan oleh kaum feminis tersebut, menunjukkan penolakan yang tegas terhadap patriarki. Melalui penolakan, lahir berbagai tawaran sistem dan model relasi baru yang lebih manusiawi dan egaliter. ${ }^{14}$

Budaya patriarki terlihat jelas dalam agama, seperti dalam semua teks keagamaan. Teks-teks Islam seperti: tafsir, hadist dan fiqih dianggap telah memberikan sumbangan yang signifikan atas langgengnya tindakan kekerasan terhadap perempuan Islam. Bias gender yang terjadi pada teks-teks Islam 
disebabkan para teolog Muslim dipenuhi prasangka sosial terhadap perempuan zaman itu.Engineer mencontohkan sebuah hadist yang terdapat dalam Ihya Ulumuddin karya AIGazali yang menyatakan, bahwa bangsa yang menyerahkan kepemimpinannya kepada seorangperempuan, bangsatersebuttidak akan pernah mencapai kesejahteraan. ${ }^{15}$ Sejarah telah membuktikan, bahwa kesejahteraan sebuah negara tidak ditentukan oleh jenis kelamin pemimpin, melainkan oleh komitmennya terhadap bangsa dan negara. Sebagaimana laki-laki, sebagian pemimpin perempuan dunia berhasil menghantarkan negaranya kepada kesejahteraan dan ketentraman.

Banyak ungkapan dalam literatur hadist yang meragukan. Contoh hadist lain adalah hadist yang diriwayatkan seorang ahli hadist yang sangat dihormati, yaitu Bukhari. Hadist tersebut berisi tentang perempuan yang disamakan seperti tulang rusuk bengkok yang jika diluruskan akan patah. Pandangan ini dianggap telah mendeskriditkan perempuan. Pandangan yang kurang positif terhadap perempuan juga ditunjukkan sebuah hadist yang menggambarkan perempuan sebagai sumber kejahatan dan diidentikkan dengan nafsu yang dapat membawa laki-laki ke dalam neraka. Hadist yang disampaikan secara berantai dari satu periwayat ke periwayat lain dalam rentang waktu yang panjang lebih dari satu abad, diduga terpengaruh oleh distorsidistorsi yang disebabkan oleh prasangkaprasangka sosial yang selalu berubah. Distorsi lain menurut Asgar Ali dapat saja berupa distorsi ingatan dari salah satu atau beberapa dari banyak mata rantai periwayat yang bersangkutan. ${ }^{16}$

Fakih mendefinisikan kekerasan sebagai suatu serangan fisik terhadap fisik maupun terhadap integritas mental psikologis seseorang. Kekerasan terhadap manusia didasarkan berbagai sebab. Salah satu sebab terjadinya kekerasan terhadap jenis kelamin tertentu karena adanya anggapan gender (gender-related-violence) dan salah satu sumber kekerasan gender adalah tafsiran umat beragama terhadap keagamaannya. ${ }^{17}$

Jika Nabi sebagai rujukan umat Islam, seyogianya umat Islam menghormati sesama manusia terutama perempuan karena Nabi sangat menghormati dan bersimpati kepada perempuan.Nabi memandang perempuan sebagai kelompok yang lebih lemah dari lakilaki di masyarakat. Penghargaan Nabi yang besar terhadap perempuan telah melampaui zamannya. Sebagai contoh, ketika seorang perempuan (anak dari sahabat beliau) mengadukan perlakuan kasar suaminya dengan telah melakukan pemukulan. Nabi memberikan hak kepada perempuan itu untuk balas memukul kepada suaminya, tetapi ditahan oleh ayat yang turun karena sikap tersebut dianggap terlalu radikal sehinggajika diterapkan akan menimbulkan pergolakan sosial. Sikap penghargaan yang besar Nabi terhadap perempuan ditunjukkan Asgar Ali Engineer melalui isi khutbah Nabi yang disampaikan saat hajjat al-wada (ibadah haji terakhir) berikut ini. "Perlakukanlah perempuan dengan baik karena mereka adalah penolongmu dan (bantulah mereka) yang tidak dalam posisi mengatasi masalah mereka sendiri. Takutlah kepada Allah dalam hal yang berkaitan dengan perempuan karena sesungguhnya engkau telah mengambil mereka atas jaminan Allah dan telah menjadikan mereka halal bagimu dengan kalimat Allah."18

Pernyataan tersebut menunjukkan sikap sempurna Nabi terhadap perempuan. Nabi adalah sosok bijaksana sehingga tidak mungkin membuat pernyataan yang bertentangan dengan semangat AI-Qur'an, 
meskipun mempertimbangkan sisi praktis pada zamannya. Nabi yang juga seorang pembaharu sosial besar tidak mungkin sama sekali mengabaikan situasi sosialnya sehingga beberapa kompromi diambil, tetapi kompromi tersebut tidak akan bertentangan dengan visi dan semangat pembaharuan yang diperjuangkannya.

\section{Kekerasan M enurut Taoisme-Islam}

Sekiranya feminis menganggap kekerasan sebagai akibat dari sistem patriarki sehingga sistem partiarki harus dilawan, Taoisme Islam sebagaimana yang dikemukakan feminis muslim Sachiko Murata memandang kekerasan sebagai dampak dari dominasi sifat maskulin (yang) yang ditunjukkan secara berlebihan. Sifat maskulin dalam konteks ini bukan maskulinitas biasa, melainkan merupakan maskulin negatif yang berkaitan dengan jiwa yang terarah pada bumi (bukan jiwa yang terarah pada ruh dengan sifat-sifat langit). Ciri-ciri sifat bumi meliputi empat unsur, yaitu tanah atau bumi, air, udara dan api (earth, water, air and fire). Jiwa yang menguasai kejahatan dihubungkan dengan api dan api dikaitkan dengan setan atau jin yang diciptakan dari api. ${ }^{19}$

Api adalah simbol dari nafsu, ambisi, keangkuhan, keserakahan, kesombongan dan berbagai tindakan kekerasan lain. Api dilambangkan sebagai sumber segala kejahatan di muka bumi. Sifat-sifat api menuntutpenegasan diri dan aktual isasi dalam bentuk kekerasan. Murata mengikuti sufi Mu'ayyid Al-Din Al-Jandi dalam menjelaskan hubungan Adam dan Iblis saat Iblis menolak bersujud di hadapan Adam melalui uraian tentang kualitas api. Alasan penolakan Iblis adalah karena api yang merupakan asal ciptaannya dianggap lebih baik dan lebih tinggi kedudukannya dari tanah (unsur asal penciptaan Adam). Menurut Murata, jiwa yang dikuasai sifat-sifat api akan memandang substansinya sendiri sebagai unsur terbaik. Jiwa menolak keterkaitannya dengan substansi lain di luar dirinya sebagaimana I blis menolak keterkaitan cahayanya dengan sesuatu yang lain di luar dirinya. Fitrah api yang berapi-api menganggap cahayanya sebagai cahaya murni tanpa mampu melihat keterbatasan dirinya. ${ }^{20}$

Kekerasan terjadi selain karena sifat maskulin negatif (yin), juga karena dominasi sifat feminin (yin) negatif yang menguasai jiwa manusia.Sifat feminin negatif memiliki ciri yang bertentangan dengan sifat feminin positif. Jika sifat feminin positif menyerah dan tunduk pada Allah (ruh yang terarah pada Allah), feminin negatif menyerah dan tunduk pada sifat-sifat binatang yang disimbolkan dengan anjing, babi dan setan ${ }^{21}$.

Seluruh perilaku manusia menurut Murata, berkaitan erat dengan posisi manusia sebagai alam kecil atau mikrokosmos yang menjadi bagian dari alam besar (makrokosmos). Mikrokosmos dan makrokosmos sama-sama berupaya mewujudkan Metakosmos (Tuhan) dan menjadikan Metakosmos sebagai tujuan. Manusia sebagai mikrokosmos memiliki dua dimensi dasar, yaitu yang tak terlihat (bersifat rohani) dan yang terlihat (bersifat jasmani). Kedua dimensi tersebut, menjadi titik tolak sifat manusia. Sifat manusia dapat meninggi naik mengarah pada dimensi tak terlihat seperti sifat malaikat, dapat pula menurun mengarah pada sifat jasmani, seperti sifat setan dan dapat menyebar sebagaimana sifat hewan. Sifat menyebar menurut Murata meliputi: sifat binatang buas (bahima, sutur) berupa kecenderungan untuk mengumbar nafsu (syahwah) dan sifat binatang pemangsa 
(siba) berupakecenderungan amarah (ghadhab). Keduanya bisa menjadi positif ketika nafsu berwujud sebuah kekuatan pemenuhan kebutuhan fisik manusiawi seperti makanminum dan ketika amarah berwujud sebuah kekuatan pertahanan diri (dari ancaman yang membahayakan) atau perbuatan tindak kekerasan yang didesak oleh keadaan. Keduanya tunduk terhadap indera malaikat atau sifat malaikat. Sifat-sifat malaikat cenderung selalu taat dan patuh pada perintah Tuhan sebagaimana isi surat Al-Tamrin: 6 yang dikutip Murata: "tidak mendurhakai Tuhan mengenai apa yang diperintahkanNya pada mereka dan melakukan apa yang diperintahkan kepada mereka".22

Sifat manusia merupakan inti manusia dan sifat manusia sepenuhnya bergantung kepada bagaimana manusia yang bersangkutan membentuknya.Secara naluriah, manusia dengan segenap sifatnya mengarahkan diri kepada tujuan hidupnya, yaitu kebahagiaan (sa'adah). Meski demikian, ada sebagian manusia yang terarah pada kesengsaraan (syaqa, atau syaqawah). Sifat manusia memiliki peran penting dalam menentukan arah pencapaian yang akan diraih. Kebahagiaan atau kesengsaraan merupakan pencapaian yang dipilih sendiri oleh manusia melalui sifat-sifat yang dimilikinya. Pencapaian di dunia menentukan pencapaian manusia di akhirat nanti. Kebahagiaan atau kesengsaraan berkaitan dengan Surga atau Neraka sebagaimana isi firman Tuhan yang dikutip Murata: "Ketika hari itu datang, tidak ada seorang pun yang berbicara, kecuali dengan izinNya. Di antara mereka ada yang bahagia dan ada yang sengsara. Adapun orang yang sengsara, tempatnya di Neraka..dan bagi yang bahagia, tempatnya di Surga." (Hud:105-108). ${ }^{23}$
Murata membuat pembedaan sekaligus tahapan kebahagiaan sebagai berikut:

Pertama, kebahagiaan bersifat instingtif diistilahkan dengan sifat hewan buas, yaitu pemenuhan kebutuhan makan-minum, tidur dan aktivitas seksual. Biasanya manusia manusia yang dipenuhi kebahagiaan tipe ini digambarkan sebagai manusia yang selalu tersibukkan pada pemenuhan kebutuhan biologis. Kedua, kebahagiaan hewan pemangsa yang berasal dari sifat hewan pemangsa, yaitu kecenderungan melakukan tindakan kekerasan yang merugikan pihak lain, seperti membunuh, marah, menipu dan berbagai tindak kekerasan lain. Manusia dengan kebahagiaan tipe ini cenderung tersibukkan dengan kebahagiaan diri sendiri meskipun harus mengorbankan orang lain. Ketiga, kebahagiaan tertinggi yang berasal dari sifat malaikat atau sifat Tuhan, yaitu perasaan akan Kehadiran Tuhan dalam setiap sikap dan perilaku. Manusia tipe ini sangat mengenal dirinya sebagai realitas batin yang mesti ditempatkan sebagai raja yang menguasai diri secara penuh agar selaras dengan-Nya. Manusia yang dipenuhi kebahagiaan tipe ini menempatkan dimensi lahir hanya sekedar pengikut atau pelayan yang tunduk pada realitas ruhani. Menurut Murata, manusia yang menyelami kedalaman dimensi ruhani (batin) selalu berada dal am situasi “Kehadiran Tuhan" yang oleh orang awam disebut sebagai "surga" (bahagia tanpa dosa). Dengan demikian, surga dan neraka merupakan sebuah situasi yang diciptakan manusia sejak di dunia. ${ }^{24}$

Bertitik tolak dari penjelasan di atas, tindakan kekerasan secara umum terjadi karena jiwa mengarahkan perhatiannya kepada sifat-sifat ketubuhan (api) dan 
Fatrawati Kumari: Agama dan Kekerasan Terhadap Perempuan (Analisis Gender dan Filsafat Taoisme-Islam)

membiarkan terarah pada pencapaian kebahagiaan lahiriah yang bersifat hewani (pemangsa) ketimbang kebahagiaan batiniahilahiah. Jiwa dibiarkan berada dalam dominasi dimensi maskulin (yang) negatif dan dimensi feminin (yin) negatif ketimbang dimensi maskulin (yang) positif dan dimensi feminin (yin) positif. Dengan kata lain, jiwa dibiarkan berada dalam ketidak-seimbangan. Ketidak-seimbangan jiwa manusia sebagai mikrokosmos akan membawa pengaruh pada ketidak-seimbangan makrokosmos, yaitu situasi sosial dan lingkungan sekitar yang meliputi dimana manusia tersebut berada.

Perempuan sebagai salah satu bagian dari korban tindakan kekerasan secara sengaja dibiarkan menjadi objek penderita. Perempuan dianggap sebagai "dzat" nomor dua sehingga relasi yang terbangun masih hirarkis dan subordinat, bukan setara-komplementaris. Jika perempuan dipandang sebagai manusia sempurna sebagaimana laki-laki dengan dimensi maskulin (yang) dan dimensi feminin (yin), maka perilaku kekerasan terhadap perempuan tidak akan terjadi. Sesungguhnya perempuan sama dengan laki-laki. Jika laki-laki memiliki dimensi maskulin dan feminin, perempuan juga demikian. Kedua dimensi tersebut meskipun tampak dualis, tetapi bersifat komplementaris, yaitu saling berkaitan dan melengkapi. Sifat dualiskomplementaris kedua dimensi tersebut juga tergambar pada laki-laki dan perempuan. Keduanya berbeda dan bertolak belakang sekaligus saling memerlukan dan saling melengkapi. Dengan demikian, perempuan melalui segenap dimensinya tersebut dapat mencapai kesempurnaan material dan spiritual sebagaimana laki-laki.

\section{KESIM PULAN}

Tindakan kekerasan terhadap perempuan tidak dibenarkan oleh agama, tetapi telah menjadi persoalan agama karena sejarah membuktikan, bahwa agama telah dijadikan sebagai alat pembenar. Agama dengan model legalis-formal patriarki sangat strategis bagi pelanggengan tindakan kekerasan terhadap perempuan.

Analisis gender dan Taoismelslam membantu agama agar kembali pada posisi substantifnya, yaitu sebagai pembebasan dan pencerah bagi manusiayang menjunjungtinggi harkat martabat manusia sebagai khalifatullah di mukabumi. Agama dalamkonteksini harus menampilkan totalitas eksistensinya yang seimbang, yaitu sebagai agama yang kuat dan berwibawa dengan dimensi maskulin (yang), sekaligus sebagai agama yang lembut, hangat dan menentramkan dengan dimensi feminine (yin) yang dikandungnya.

\section{Endnotes:}

1 Lihat Rifka Annisa, Laporan Kekerasan Terhadap Perempuan (KDRT), Yogyakarta: Women Crisis Center: Rifka Annisa, Yogyakarta, 2007.

2 Lihat Komisi Nasional (Komnas) Perlindungan Perempuan dan Anak, Catatan Tahunan Komisi Nasional Peremuan Tahun 2009, Jakarta: Komnas Perlindungan Perempuan dan Anak, 2009.

3 Informasi selengkapnya terdapat dalam: $\mathrm{H}$ arian Umum Banjarmasin Post, Senin, 31 Oktober 2011.

4 Harian Umum Banjarmasin Post, Selasa, 1 November 2011.

5 Harian Umum Banjarmasin Post, Kamis, 3 November 2011.

6 Rifka Annisa, Laporan Kekerasan Terhadap Perempuan (KDRT), (Yogyakarta: Women Crisis Center: Rifka Annisa, Yogyakarta, 2007.

7 Lihat dalam: Humm, Maggie, Ensiklopedia Feminisme, judul asli: "Dictionary of Feminist Theory" alih bahasaM undi Rahayu, Yogyakarta: 
Fajar Pustaka Baru, 2003, cetakan pertama, h. 332, 484.

8 Pandangan Berger dikutip Said dalam: Said, Nur, 2005, Perempuan dalam Himpitan Teologi dan HAM, Yogyakarta: Penerbit Pilar, 2005, h. 15.

9 Marcoes, Lies, Perempuan, Islam dan Ham: Tantangan dari Teori ke Praksis, dalam Nur Said "Perempuan dalam Himpitan Teologi dan HAM, Yogyakarta: Pilar, 2005, h. xxxii.

10 Marcoes, Lies,Perempuan, Islam dan Ham: Tantangan dari Teori ke Praksis, h. xxxv.

11 Humm, Maggie, Ensiklopedia Feminisme, h. 484 486.

12 Engineer, Asgar Ali, Hak-Hak Perempuan dalam Islam, terj."The Right of Women in Islam" oleh Farid Wajdi dan Cici FarhaAssegaf, Y ogyakarta: Yayasan Bentang Budaya, 1994. h. xiii-xxvii.

13 Moore, Harietta L, Feminism and Antropology, Cambridge: Politiy Press, 1988, h.6.

14 Lihat bagaimana patriarki dianggap sebagai bahaya bagi eksistensi perempuan dalam: Humm, Maggie, Ensiklopedia Feminisme, h. 332335.

15 Engineer, Asgar Ali, Hak-Hak Perempuan dalam Islam, h. 206.

16 Lihat Iebih jauh pandangan Engineer dalam: Engineer, Asgar Ali, Hak-Hak Perempuan dalam Islam, h. 206.

17 Fakih, Mansour, et.al.,Membincang Feminisme: Diskursus Gender dalam Perspektif Islam, Surabaya: Risal ah Gusti, 2000, h. 55.

18 Engineer, Asgar Ali, Hak-Hak Perempuan dalam Islam, h. 207.

19 Murata, Sachiko, The Tao of Islam: A Saurce Book on Gender Relationship in Islamic Thought, New York: State University of New York Press, 1992, h. 269.

20 Murata, Sachiko, The Tao of Islam: A Saurce Book on Gender Relationship in Islamic Thought, h. 269270.

21 Murata, Sachiko, The Tao of Islam: A Saurce Book on Gender Relationship in Islamic Thought, h. 271272.
22 Murata, Sachiko, The Tao of Islam: A Saurce Book on Gender Relationship in Islamic Thought, h. 225230.

23 Lihat kutipan Murata tentang ayat tersebut dalam M urata, Sachiko, The Tao of Islam: A Saurce Book on Gender Relationship in Islamic Thought, $\mathrm{h}$. 230.

24 Murata, Sachiko, The Tao of Islam: A Saurce Book on Gender Relationship in Islamic Thought, h.230231.

\section{DAFTAR PUSTAKA}

Annisa, Rifka, Terhadap Perempuan Berbasis Gender, Yogyakarta: The Global Fund for Women, 2007.

Banjarmasin Post, Senin, 31 Oktober 2011. , Selasa, 1 N ovember 2011. , Kamis, 3 N ovember 2011.

Engineer, Asgar Ali, Hak-Hak Perempuan dalam Islam, terj. "The Right of Women in Islam" oleh Farid Wajdi dan Cici Farha Assegaf, Yogyakarta: Yayasan Bentang Budaya, 1994.

- Pengantar: Esensi Agama adalah NilaiNilainya, Bukan Ritual-Ritualnya, dalam M. yasir Alimi "Jenis Kelamin Tuhan", Yogyakarta: Lkis, 2002.

Fakih, Mansour, et.al., Membincang Feminisme: Diskursus Gender dalam Perspektif Islam, Surabaya: Risalah Gusti, 2000.

Humm, Maggie, Ensiklopedia Feminisme, judul asli: "Dictionary of Feminist Theory" alih bahasa Mundi Rahayu, cetakan pertama, Yogyakarta: Fajar Pustaka Baru, 2003.

Komisi Nasional (Komnas) Perempuan, Catatan Tahunan Komisi Nasional Perempuan Tahun 2009, Jakarta, 2009. 
Fatrawati Kumari: Agama dan Kekerasan Terhadap Perempuan (Analisis Gender dan Filsafat Taoisme-Islam)

Marcoes, Lies, Perempuan, Islam dan Ham:

Tantangan dari Teori ke Praksis, dalam Nur

Said “Perempuan dalam Himpitan Teologi

dan HAM, Yogyakarta: Pilar, 2005.

Moore, Harietta L, Feminism and Antropology, Cambridge: Politiy Press, 1988.

Murata, Sachiko, The Tao of Islam: A Saurce Book on Gender Relationship in Islamic Thought, New York: State University of New York Press, 1992.

Said, Nur, 2005, Perempuan dalam Himpitan Teologi dan HAM, Yogyakarta: Pilar, 2005. 